\section{Miasis cutánea forunculosa causada por Dermatobia hominis}

\section{Cutaneous furuncular myasis caused by Dermatobia hominis}

\section{Sr. Editor:}

La miasis cutánea forunculosa corresponde a una infestación de la piel causada frecuentemente por la larva de la mosca Dermatobia hominis. Ocurre en países de climas tropicales y es la cuarta causa de enfermedades cutáneas del viajero. Los casos reportados en Chile son escasos y son producidos en pacientes que han viajado a zonas endémicas de América Central y Sur, por lo cual su diagnóstico requiere alto grado de sospecha cuando existen antecedentes epidemiológicos ${ }^{1}$. Presentamos un caso de miasis forunculosa causada por Dermatobia hominis en una paciente con antecedentes de estadía reciente en Brasil.

Mujer de 23 años, chilena, con el antecedente de viaje por motivos laborales a una plantación de hortalizas y bananas, al sector rural de Sao Paulo (Barra do Turbo), Brasil, por un período de 8 meses. Presentó historia de 1 mes y medio de evolución con aumento de volumen eritematoso localizado en región dorso-lumbar izquierda asociado a dolor intermitente tipo puntada. En el examen físico se observó una lesión nodular eritematosa con un orificio central y exudado seropurulento (Figura 1A). La paciente advirtió la salida espontánea de una larva a través del orificio de la lesión (Figura 1B). La larva era de color pardo amarillento, con aproximadamente $2 \mathrm{~cm}$ de largo y presentaba varias hileras de pequeñas espinas negras de disposición antero-posterior en su extremo cefálico. La larva fue identificada como Dermatobia hominis, estadio III. Dado el contexto clínico, epidemiológico y las características morfológicas de la larva se diagnosticó una miasis forunculosa por Dermatobia hominis. Se indicó tratamiento con flucloxacilina oral, $500 \mathrm{mg}$ cada $8 \mathrm{~h}$ por 7 días, considerando la presencia de eritema, dolor y exudación. Acudió a control 1 semana después, con excelente evolución, sin signos de infección y sólo hiperpigmentación postinflamatoria.

La miasis puede ser clasificada de acuerdo al área de localización: cutánea, nasofaríngea, ocular, intestinal y urogenital ${ }^{2}$. La miasis cutánea es la forma clínica más frecuente y según sus manifestaciones clínicas se divide en miasis forunculosa, migratoria y traumática (heridas). En América, la causa más frecuente de miasis forunculosa es producida por la larva de la mosca Dermatobia hominis, perteneciente a la familia Oestridae ${ }^{2,3}$. Se distribuye desde México hasta el norte de Argentina, principalmente en regiones cálidas y húmedas con altitud menor que $1.000 \mathrm{~m}^{2-4}$. Muchos pasajeros adquieren este parásito en zonas endémicas y regresan a sus países antes de completar el desarrollo larval. Dermatobia hominis tiene un inte-

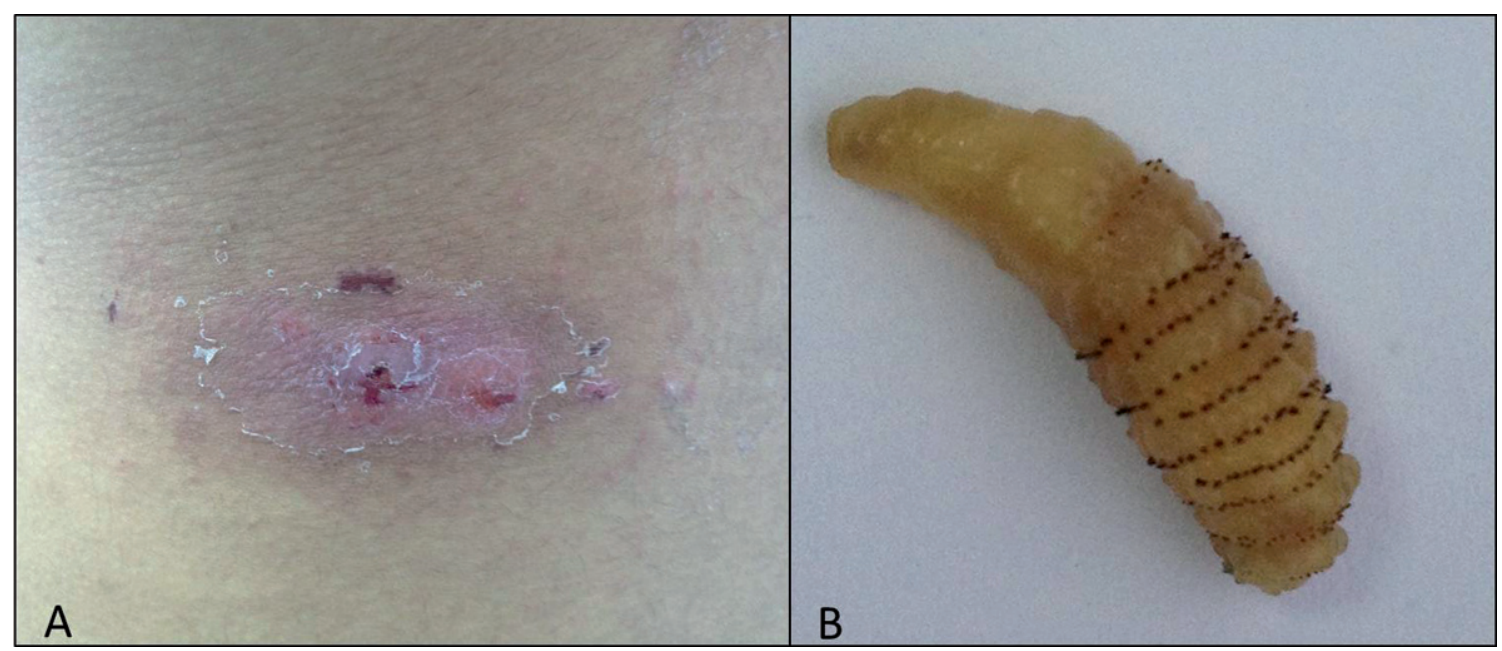

Figura 1. A. Nódulo eritematoso de aproximadamente $3 \mathrm{~cm}$ de diámetro con orificio central y exudado seropurulento localizado en la región dorso-lumbar izquierda. B. Larva estadio III identificada como Dermatobia hominis. 
resante ciclo biológico: la especie necesita que sus larvas se desarrollen en un hospedero vertebrado de sangre caliente (mamíferos y accidentalmente el hombre), constituyendo una miasis obligada ${ }^{1}$. Debido a que la mosca no es hematófaga, deposita sus huevos en el abdomen de artrópodos hematófagos que actúan como transportadores (mosquitos). Cuando los mosquitos pican al hospedero, emergen pequeñas larvas que penetran en la piel del hospedero, donde se alimentan, crecen y permanecen alrededor de 5 a 10 semanas, para finalmente abandonar la piel y caer a la tierra, en la cual se transforman en pupas y posteriormente en insecto adulto ${ }^{1,2,4}$.

Las lesiones pueden ubicarse en cualquier área expuesta de la piel, siendo frecuentemente afectado el cuero cabelludo, la cara y las extremidades ${ }^{1,2}$. En general, las lesiones son únicas y cada lesión presenta una sola larva. Las lesiones son nodulares y tienen aspecto de forúnculo, miden 2 a $3 \mathrm{~cm}$ de diámetro y pueden producir episodios de dolor agudo y prurito $^{2-4}$.

Los diagnósticos diferenciales más frecuentes son el quiste epidérmico sobreinfectado, las piodermias, las picaduras de insectos sobreinfectadas, la larva cutánea migrans, la tungiasis y la leishmaniasis ${ }^{1-3}$.

Las complicaciones más importantes son la sobre infección bacteriana y el tétano ${ }^{1-3,5}$. Se han reportado casos de miasis cerebral fatal, producto de la infestación de la piel que cubre las fontanelas de infantes y niños pequeños ${ }^{5}$.

El tratamiento consiste en la extracción de la larva, la cual puede ser removida en forma manual al presionar el nódulo o realizar una pequeña incisión quirúrgica en el centro de la lesión y posteriormente presionar ${ }^{2,3,6}$. Otras alternativas son el uso de apósitos que ocluyen el orificio por donde la larva respira, para lo cual se han usado gasas que contienen aceites minerales, vaselina o incluso un trozo de tocino ${ }^{2,3}$. En cuadros más avanzados, la larva puede salir en forma espontánea por el orificio de la lesión. Una vez removida la larva el nódulo residual se resuelve en forma completa sin dejar cicatriz ${ }^{2,3}$.

Debido a un incremento en el turismo internacional, se debe aconsejar el uso de repelentes de mosquitos que contengan dietil-toluamida (DEET) y el uso de ropa de algodón larga y ajustada a pacientes que viajan a zonas endémicas ${ }^{2,6}$. Debido a que este tipo de miasis cutánea es poco conocida en nuestro medio, queremos destacar que la presencia de una lesión forunculosa en un paciente con antecedentes de viaje reciente a un área endémica debe hacer sospechar e investigar esta parasitosis.

\section{Carlos Pastor, Gastón Briceño, Fabiola Schafer Departamento de Especialidades Médicas, Facultad de Medicina, Universidad de La Frontera, Temuco, Chile.}

\section{Referencias}

1. Schenone H, Apt W, Vélez R, Bustamante S, Sepúlveda C, Montaldo G, et al. [Imported myiasis: 7 cases of cutaneous parasitism caused by Dermatobia hominis flie larvas]. Rev. Med Chile 2001; 129 (7): 786-8.

2. Robbins K, Khachemoune A. Cutaneous myiasis: a review of the common types of myiasis. Int J Dermatol 2010; 49 (10): 1092-98.

3. Maier H, Honigsmann H. Furuncular myiasis caused by Dermatobia hominis, the human botfly. J Am Acad Dermatol 2004; 50 (2 Suppl): S26-30.

4. García-Cubillana JM, Mingo J, Blanco J, Iravedra JA. Absceso de tórpida evolución. Dermatobia hominis. An Pediatr (Barc) 2009; 71 (2): 175-76.

5. Rossi MA, Zucoloto S. Fatal cerebral myiasis caused by the tropical warble fly, Dermatobia hominis. Am J Trop Med Hyg 1973; 22 (2): 267-9.

6. Vijay K, Kalapos P, Makkar A, Engbrecht B, Agarwal A. Human botfly (Dermatobia hominis) larva in a child's scalp mimicking osteomyelitis. Emerg Radiol 2013; 20 (1): 81-3.

Fuente de apoyo financiero: Ninguna.

Correspondencia a:

Dra. Fabiola Schafer

Av. Claro Solar 115, Facultad de Medicina, Universidad de la

Frontera, Temuco, Chile.

E-mail: fdschafe@gmail.com 